\title{
Hacer Historia es Hacer Vida: El Colegio Refugio de la Infancia de Antímano, Venezuela - 1896-2010. Parte I (1896-1998)
}

Fazer Historia é Fazer Vida: O Colégio Refúgio da Infância de Antímano, Venezuela 1896-2010. Parte I (1896-1998)

Making History is Making Life: College Children's Refuge of Antímano, Venezuela 1896-2010. Part I (1896-1998)

Dominique Gay-Sylvestre

Universidad de Limoges (DYNADIV), Francia

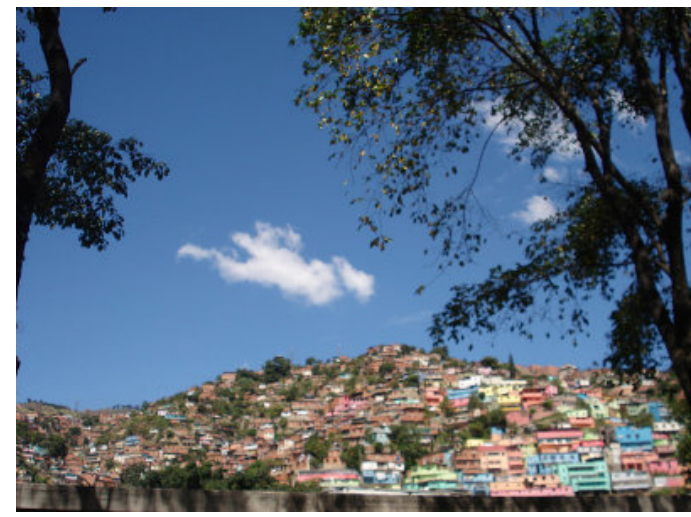

Dominique Gay-Sylvestre, Barrio de Antímano, Venezuela

\begin{abstract}
Resumen
En 1896, Julia Duplat, de origen francés, decide socorrer a las niñas desamparadas de los barrios miserables de Caracas, con la creacion de una casa Refugio. A principios del siglo XX, enferma, deja en manos de la congregación francesa de San José de Tarbes, el cuidado de su obra. En medio de las calamidades que asolan la república venezolana, de las numerosas guerras civiles que golpean a la incipiente nación venezolana, crece el refugio ya hecho una escuela para niñas. Ritmada por las múltiples leyes educativas promulgadas a lo largo del siglo, por los favores o los ataques de los diferentes mandatarios, la vida cotidiana de las tarbesianas es una lucha constante para mantener a flote el « hogar-escuela » que han construido para sus alumnas.

Palabras clave: Historia ; Venezuela ; educación privada ; educación pública ; sociedad; siglo XIX; siglo XX; congregación de San José de Tarbes ; Refugio de la Infancia.
\end{abstract}

\begin{abstract}
Resumo
Em 1896 Julia Duplat, de origem francesa, decide socorrer as meninas desamparadas dos bairros pobres de Caracas com a criação duma casa-refúgio. No começo do século vinte, doente, ela deixou nas mãos da congregação francesa de São José de Tarbes o cuidado da sua obra. No meio das calamidades que assolam a república venezuelana e das numerosas guerras civis que açoitam a incipiente nação, cresce o refúgio convertido jà numa escola para meninas. Ritmada pelas múltiplas leis educativas promulgadas ao longo do século e pelos favores ou pelos ataques dos diferentes mandatários, a vida cotidiana das tarbesianas é uma luta constante para levar à frente o "lar-refúgio" que elas construíram para as suas alunas.

Palavras chave: História ; Venezuela ; educação privada; educação pública; sociedade, século XIX, século XX, congregação de São José de Tarbes, Refúgio da Infância.
\end{abstract}

\begin{abstract}
In 1896 Julia Duplat, of French extraction, decides to succour the vulnerable girls in the slums of Caracas with the foundation of a shelter house. As whe was ill at the beginning of the 20th century she left her charity in the caring hands of the French congregation of Saint Joseph of Tarbes. Among the disasters that befall the Venezuelan republic and the numerous civil wars that grip the incipient nation, the shelter, already a girls' school, grows and develops. Marked by the multiple education laws all along that century and by the favours or the attacks of the different heads of state, the daily life of the Sisters of Saint Joseph of Tarbes is a constant struggle to keep afloat the "shelter home" that they built for their pupils.

Key words: History; Venezuela; private education; public education; society; 19th century; 20th century; congregation of San José de Tarbes; Childhood Shelter.
\end{abstract}




\section{Introducción}

Llegué por primera vez a Venezuela a mediados del año 2000 movida por mi interés en el desarrollo de la trayectoria de la congregación francesa del Buen Pastor de Angers, cuyos inicios pastorales en tierra hispanófona había estudiado en $\mathrm{Cuba}^{1}$.

En realidad por mucho que porfiara en buscar informes sobre dicha institución tenía la impresión de que ella se asemejaba más bien a la arlesiana de la historia y que aunque no era fruto de mi imaginación su existencia, me era imposible encontrar su lugar de asentamiento.

En cambio, el nombre, el renombre incluso, de otra congregación francesa, la de San José de Tarbes ${ }^{2}$, aparecía de manera recurrente como atada a la historia del pueblo venezolano desde finales del siglo XIX.

En 1889, en efecto, escapando de las persecuciones consecutivas a la política de laicización del gobierno francés y a petición del presidente venezolano Rojas Paúl $^{3}$, un pequeño grupo de ellas había llegado a Venezuela (Gay-Sylvestre, 2004) para encargarse del hospital Vargas de Caracas ${ }^{4}$. A lo largo de los años, había ido creciendo su implicación en la sociedad venezolana. $\mathrm{Su}$ obra, tanto hospitalaria como educativa ${ }^{5}$, había marcado y seguía haciéndolo el devenir y la formación ciudadana de centenares de venezolanos.

Esta singularidad en un país en que las relaciones entre el Estado y la Iglesia católica, sin ser antagónicas eran simplemente corteses había despertado mi curiosidad. Emprendí entonces una serie de investigaciones susceptibles de aclarar el papel desempeñado por la congregación francesa.

El Refugio de la Infancia ubicado en Antímano ${ }^{6}$, al oeste del Municipio Libertador en las cercanías de Caracas, entre los numerosos establecimientos y fundaciones de las tarbesianas esparcidos por el territorio venezolano, parangón social y educativo, producto de un continuo esfuerzo de servicio comunitario dinámico, participativo y creador de inicativas, constituía una de las posibles claves para la aprensión de los lazos que unían la Congregación de San José de Tarbes a la nación venezolana.

A partir de 1912 en que se iban a hacer cargo de él las religiosas, progresivamente se había ido conformando y adaptando el Refugio no sólo a las exigencias nacionales educativas sino también a la orientación tarbesiana de una necesaria convergencia entre familia e institución educativa en el ámbito de la comunidad local.

En el fortalecimiento de la opción por una educación popular, la Congregación de San José de Tarbes iba a optar deliberadamente por realzar valores humanos esenciales en que prevalecerían unos modales de conducta responsable y crítica.

A pesar de los múltiples aconteceres que señalarían su historia, las turbulencias individuales y colectivas, el transcurrir cotidiano a menudo trabajoso, el Colegio Refugio de la Infancia, hoy día permanece fiel a sus exigencias de calidad educativa y a su ideal de sociedad justa, capaz de insertarse en un proceso de desarrollo socio-cultural latinoamericano.

«Hacer historia es hacer vida »: bien lo han integrado las religiosas en sus respuestas a la colectividad y en sus acciones a favor de los más desfavorecidos. Altamente involucradas en la promoción y en el devenir del ser humano, se fundamentan en las luchas y crisis del pasado histórico venezolano para implantar en la mente del futuro ciudadano la indispensable y voluntaria incorporación en un mundo nuevo, más digno y cristiano.

La historia del Refugio de la Infancia es la historia de una obra social y educativa, de un empeño continuo en la construción de un modelo humano significativo que cumpla digna y eficazmente con unos imperativos de cambios basados en una opción preferencial hacia los pobres.

Presa de los sobresaltos que sacuden la construcción de la nación venezolana, el Refugio de la Infancia sigue, sin naufragar, el rumbo que se ha fijado. $\mathrm{Su}$ fuerza, la encuentra en un clima en que prevalecen la confianza, el respeto y la voluntad de superación. Surgen así una familia, otra, dinámica, accesible, atenta, un segundo hogar, en que se construyen y modelan nuevas perspectivas, esperanzadoras siempre.

Será el camino emprendido por el refugio durante un siglo. Luego, con el advenimiento, en 1999, del presidente de la República Bolivariana de Venezuela, vendrán otros tiempos, otros compromisos, con enfoques educativos distintos, inspirados y apoyados en gran parte por la isla hermana de Cuba. Se aparta la nación de un pasado esterilizante para sumirse en el nacimiento de una sociedad aferrada a la estructuración y disposición de espacios de creación nuevos y regeneradores.

\section{Fundación}

\section{Orígenes}

El segundo mandato del presidente Joaquín Crespo (1892-1898) hunde a la República venezolana en un estado de profunda inestabilidad social. La descomposición de gran parte de la sociedad recae principalemente en las capas más humildes. Caracas no escapa de la miseria ambiente. Con el apoyo de varias damas caraqueñas y de un grupo de familias dadivosas, una señorita de nacionalidad francesa, Julia Duplat, persona de « corazón grande y generoso» (Archivos de Antímano), adquiere, el 8 de septiembre de 1896, una casa situada en la Parroquia ${ }^{7}$ Santa Rosalía ${ }^{8}$, para acoger en ella a niñas y niños de todas las edades, hasta de meses, huérfanos y desamparados.

Desde el principio, para poder subsistir, el orfanato tiene que lidiar con privaciones, obstáculos 
y sacrificios de todas clases. Venezuela atraviesa momentos confusos : contra la voluntad popular, J. Crespo que pretende prolongarse en el mando, impone como sucesor a un hombre de poco peso el general Ignacio Andrade 9 . Su autocratismo provoca la reacción violenta de los partidarios del general José Manuel Hernández opuestos a la imposición de una nueva dictadura disfrazada. El país conoce entonces enfrentamientos escarnecidos durante los cuales el ex presidente, que defiende el régimen de su protegido, hallará la muerte. Por si fuera poco, a la guerra civil se sumen en 1898 unas epidemias de viruela y de peste que provocan la muerte de numerosos venezolanos, entre los más pobres y causan verdaderos estragos entre los más frágiles de ellos : los niños. Los hospitales de Caracas $^{10}$ y de los Teques ${ }^{11}$ están atestados. El mismo internado del Refugio está requisado.

$\mathrm{Ni}$ siquiera recuperado el país de los desastres provocados por la epidemia cuando sufre Caracas, en 1900, un sismo de gran magnitud : muertes y ruinas constituyen entonces el lote cotidiano de una población perdida y sin defensa que los recurrentes movimientos para derribar al presidente Cipriano Castro dejan sin reacción

La negativa al pago de reclamaciones de nacionales europeos por los daños sufridos a raíz de los conflictos internos provoca la intervención de los cañoneros anglogermanos en 1902 seguida, un año después, por el bloqueo impuesto por los acorazados franceses e italianos.

Es pues un país exhausto y dolido por la epidemia de peste bubónica ${ }^{12}$, las incursiones de langostas (en los Andes en particular), las inundaciones y sequías repetidas, que asiste, en 1908, al advenimiento del nuevo presidente de la República Juan Vicente Gómez, esperanzado en las declaraciones reiteradas del candidato de « paz », « unión » $\mathrm{y}$ 《 trabajo » para todos, en el territorio.

El Refugio, por su parte, no ha naufragado. La voluntad férrea y la labor incansable de su fundadora y de las benévolas que la acompañan no lo han permitido. Pero, se ha agotado la señorita Duplat en su tarea... Sintiéndose delicada de salud, acude a la madre Saint Simon $^{13}$, Superiora Regional de las Hermanas de San José de Tarbes, para que ésta consienta en tomar el Refugio a su cargo. En el mismo momento, por orden del general Juan Vicente Gómez ${ }^{14}$, se cierra y se transfiere la leprosería de Cabo Blanco ${ }^{15}$, a la isla de la Providencia. Las religiosas de San José de Tarbes que cuidaban de los enfermos son sustituidas por las religiosas españolas de Santa Ana.

La aceptación de la superiora es, pues, rápida y el 2 de diciembre de 1912 el Refugio de la Infancia es ya propiedad de las religiosas de San José de Tarbes. Las Hermanas Celina, Febronie y más adelante María Sandáez forman la primera comunidad, iniciando en él la tarea educativa a la que se dedican las tarbesianas desde su instalación en Venezuela.
Éstas han conquistado el afecto y el reconocimiento de la población venezolana. $\mathrm{Su}$ obra misionera es ampliamente reconocida ${ }^{16}$ por las autoridades venezolanas y francesas locales. La labor de beneficiencia y de educación incipiente iniciadas por la señorita Duplat es un desafío más que la congregación entiende cumplir a cabalidad.

\section{Nuevo rumbo}

Ante el analfabetismo crónico imperante, el nuevo ministro de educación Gil Fortoul cambia la orientación seguida hasta entonces en materia de instrucción pública insistiendo en la necesaria calidad no sólo en la instrucción sino también en la formación de maestros en escuelas normales. La escuela, declara, ya no puede ser empleada para hacer beneficiencia pública.

El Refugio de la Infancia debe adoptar otra orientación so pena de ver arruinados todos los esfuerzos realizados hasta entonces. Su transformación pasa necesariamente por la aceptación e implantación, en su seno, de la escuela graduada - propuesta gubernamental que trata de llevar a cabo en su gestión ministerial, Gil Fortoul.

Dicha escuela, también denominada escuela integral, no resulta algo novedoso para las tarbesianas que ya se valen de ella en sus instituciones educativas. En cambio, por muy atractiva que sea, su instalación aparece compleja y azarosa para el Refugio que carece de fondos suficientes para constituir varios grupos de alumnas, más o menos homogéneos, al solo cuidado de una maestra.

A pesar de todo, la fórmula es adoptada $\mathrm{y}$, a partir de 1911, se llevan a cabo la concentración de las escuelas y el establecimiento de la graduación de la enseñanza, en Caracas y en las localidades más populosas del país. Asimismo, se incorporan, como asignaturas obligatorias, la educación física, los deportes, los trabajos manuales, así como la salud del niño y la higiene escolar. El maestro por su parte,

(...) puede ser un profesional y debe serlo ; es decir, que aun cuando no esté en ejercicio, deben acompañarlo por vida ciertos derechos y los deberes correlativos como acompañan los suyos peculiares al médico, al ingeniero y al abogado (J.L. SalcedoBastardo, 1996, p. 98).

Pero, sometidas, como lo requiere el Código de Instrucción Pública, a la inspección de los agentes del Ministerio de Instrucción pública ${ }^{17}$, las religiosas sufren las repercusiones de las tensiones que oponen el Estado a los representantes de la jerarquía eclesiástica $^{18}$. Desacuerdos que se incrementan con la promulgación, en diciembre de 1913, del Decreto Orgánico de la Instrucción Pública sobre la libertad de enseñanza ${ }^{19}$, que refuerza el control estatal con respecto a las escuelas privadas.

Los planteles oficiales, en cambio, gozan de privilegios y monopolios. Sin embargo, el nuevo 
ministro de Instrucción Pública Dr. Felipe Guevara Rojas que, en 1913, asume el cargo, restablece criterios más liberales en las relaciones entre el Estado y la iniciativa privada en el campo educativo. Declara, en 1914, el carácter inconstitucional de algunos artículos de la Ley de Instrucción que establecía restricciones en el funcionamiento de las escuelas privadas, confortado en su decisión por el Decreto Orgánico de la Instrucción (1914) que establece claramente la libertad de enseñanza ${ }^{20}$ :

Cualquier persona en plena posesión de sus derechos civiles, podía enseñar lo que quisiera y como lo quisiera sin necesidad de solicitar licencia del Ministerio de Instrucción y sin estar sometido a ninguna relación gubernamental en cuanto a programas, textos, horarios y otras medidas dictadas para la instrucción oficial (J.L. Salcedo-Bastardo, 1996, p. 99).

Las desavenencias sufridas por el colegio tarbesiano del Paraíso ${ }^{21}$, no afectan al Refugio que sigue cumpliendo con su misión entre la población pobre del barrio.

Los efectos de la Primera Guerra Mundial empiezan a repercutirse en la economía mercantil agroexportadora (café y cacao en particular) de la lejana Venezuela, reduciendo drásticamente las fuentes de ingresos de la población y su ritmo de crecimiento. No obstante, el cambio no afecta al Refugio. En efecto, en 1916, a pesar de una epidemia de malaria que asola el país provocando repercusiones sociales, económicas, culturales e incluso políticas, aumenta el número de nóminas.

En aquel momento, la Madre Marie-Germaine ${ }^{22}$ decide el traslado del Refugio a la casa de campo del General Raimundo Andueza Palacio ${ }^{23}$, más ampolia, situada en la parroquia foránea y rural de Antímano.

El proceso de normalización de las relaciones entre la Iglesia católica con el Gobierno del Presidente Juan Vicente Gómez favorece la estrategia restauradora de aquella en Venezuela. La iniciativa privada en el sector de la educación es asumida casi esencialmente por la educación católica y las congregaciones religiosas, que además, prestan sus servicios en numerosos hospitales.

La congregación de San José de Tarbes, como otras instituciones, se beneficia de este clima providencial que repercute en un aumento substancial de las subvenciones estatales. Como consecuencia el Refugio amplía sus instalaciones. Se acondiciona la Capilla y empieza a funcionar el Externado y la Catequesis a nivel parroquial.

Pero, la peste bubónica que había permanecido bajo forma endémica se extiende de nuevo, en 1918, por todo el territorio venezolano. Eso pone de realce, una vez más, las pésimas condiciones de higiene y de salubridad existentes en el país y la incapacidad de las autoridades para enfrentarlas, pese a la creación, en 1910, del Primer Congreso de
Municipalidades destinado a aportar las respuestas urgentes indispensables, a la necesidades públicas de las localidades y regiones del país.

A la plaga de la peste, se añade la de la gripe española : Venezuela es ya un país desolado...

Ante la escasez de hospitales, el gobierno venezolano cierra todos los colegios transformándolos en centros de emergencia. El mismo Refugio se convierte en un centro de distribución de alimentos y medicinas.

Las Hermanas de San José de Tarbes que, en épocas anteriores se habían sacrificado en pro de la población, se ofrecen de nuevo para cuidar a los enfermos ; colaboran también las alumnas internas del Refugio. Alejado Antímano de los centros de distribución, las religiosas, sin preocuparse por el contagio posible, valiéndose de un asno prestado por un vecino, van distribuyendo víveres y medicamentos a los enfermos y a los necesitados que no pueden acudir al centro. La iniciativa privada religiosa, la valentía manifestada por las religiosas, el compromiso y la abnegación de las instituciones en los asilos y centros asistenciales incrementa el prestigio de la Iglesia Católica. Pero también es duro el tributo pagado en estos tiempos de necesidades apremiantes y sufrimientos continuos; también es consecuente el número de muertes entre las tarbesianas y sus alumnas...

Sin embargo, ya a partir de los años 20, se observan cambios derivados de la Primera Guerra Mundial. El desarrollo del capitalismo norteamericano repercute en el área del Caribe y de Centroamérica. En Venezuela el desarrollo del mercado interno implica el desarrollo de las fuerzas de producción y la producción de bienes y servicios para satisfacer las necesidades médico sanitarias y educativas. También empiezan a sentirse las primeras consecuencias derivadas de la expansión y explotación de la economía del petróleo.

Transcurren los años. A pesar del clima de inseguridad continuo debido a los numerosos movimientos en contra del Presidente Juan Vicente Gómez y de un foso social creciente entre las diferentes capas de la población, amparado por el apoyo brindado por el primer mandatario a la Iglesia Católica, el Refugio logra salir a flote a pesar de las dificultades. Su fama va creciendo entre la población pobre aledaña que sufre condiciones de vida precarias. Va aumentando el número de niñas internas : la mayoría de ellas proceden de hogares afectados por graves problemas socioeconómicos, en que predominan la descomposición del núcleo familiar, la delincuencia y la prostitución.

Pese al aumento de la renta petrolera, la situación de prostración económica de Venezuela es innegable ; sólo una parte mínima de esa riqueza beneficia al país. A pesar de sus esfuerzos y buena voluntad, las religiosas experimentan grandes dificultades para que siga funcionando el internado.

Para resolver una situación que se está volviendo 
crítica, la Dirección del Refugio decide establecer una lavandería en la cual las alumnas mayores aportarán su trabajo, cooperando en esa forma en el mantenimiento de la escuela. También se organiza un salón de costura. El beneficio de esta reestructuración permite mejorar la alimentación cotidiana y, asimismo, realizar algunos arreglos en la casa.

En el interín fallece el Presidente Gómez. Es sustituido por el Presidente Eleazar López Contreras. A partir de ese momento, se enfrían las relaciones entre el Estado y la Iglesia Católica. Promulgadas por el nuevo ministro de Instrucción Pública, Prieto Figueroa, las leyes de educación establecen las normas que han de regir El Estado docente y la Libertad de enseñanza, ocasionando vigorosas protestas en el seno de la institución católica.

Asimismo, las nuevas políticas públicas del Estado, marcadas por las nociones de « desarrollo social », de « progreso » y de « humanismo » van a idear proyectos orientados a :

(...) atender el mayor porcentaje de la población, que en situaciones precarias habían vivido en un medio social regido por la pobreza, el analfabetismo y las enfermedades endémicas (R.A. Uzcategui, s.n.p.).

Se trata fundamentalmente, a partir de la educación primaria en particular, de promover una nueva sociedad,

(...) más justa, incluyente, democrática y donde nuevas corrientes renovadoras de la escuela enc[uentren] campo propicio a sus aspiraciones, la formación de un hombre en sus plenas capacidades y potencialidades, con conciencia de su realidad histórica y su carácter social (R.A. Uzcategui, s.n.p.).

La Ley de educación, por otra parte, establec[e] una diferencia sustancial entre la enseñanza como facultad que todos posean libremente y el otorgamiento de títulos y certificados oficiales, que es un derecho exclusivo del Estado ((R.A. Uzcategui, s.n.p.).

manteniendo y reforzando el Estado el control sobre los planteles privados « que aspiran a hacer valer sus estudios a los efectos de otorgamientos de certificados y títulos » (R.A. Uzcategui, s.n.p.).

La vigilancia del Estado sobre los planteles privados, la promulgación, en 1943, del Reglamento de Escuelas Primarias y de Obligación Escolar ${ }^{24}$ que establece que se reparta la educación primaria en seis grados pone al Refugio en aprietos. En efecto, el establecimiento no tiene la capacidad suficiente para adaptarse a las normas impuestas por el Estado y corre el riesgo de cerrar sus puertas.

La intervención de la Madre Superiora de la Congregación ante las autoridades educativas del Estado le da un respiro al Refugio que ve su compromiso en la lucha contra el analfabetismo y la extensión de la educación popular valorado. Caracas, en particular, no logra resolver el grave problema que representan la delincuencia infantil, las pandillas y el abandono de los niños : la presencia y la labor de una iniciativa privada como la del Refugio colma unas insuficiencias patentes.

La Asociación Venezolana de Educación Católica (AVEC) que, en 1948, hace público un documento titulado Bases para una Ley de Educación adopta una orientación conforme con el ideal pregonado por el Estado. Para el proyecto católico, la educación es un instrumento de cambio social, centrado en la formación del hombre, consciente y responsable. Se trata de dispensar una educación personalizada y acompañar al niño en su crecimiento espiritual. Opción favorecida por las tarbesianas y seguida por el Refugio desde sus inicios.

\section{Otra orientación}

El derecho a la educación para todos es ya aceptado. Tanto la A.V.E.C. como el Estado saben que tienen que luchar juntos para facilitar su acceso. La aprobación de la Ley de Educación, en 1948, que se centra en un « humanismo democrático » y en un « humanismo educativo » da un gran paso adelante. Siguiendo los principios de la Escuela Nueva que considera a la educación como « un proceso integrador del individuo desde el punto de vista de su desarrollo biológico y su desenvolvimiento mental y moral» (R. Fernandez Heres, 1997, p. 226) se tiende a la mayor incorporación de niños y niñas al sistema de educación formal.

Esta medida repercute en el manejo del Refugio cuyas autoridades se ven obligadas a cambiar los planes fijados para su desenvolvimiento. A partir de 1950, las internas que deben seguir el nuevo pensum de estudios (obligatorio y fijado por el Estado) no pueden atender la lavandería que tanta ayuda había proporcionado en los años anteriores.

La situación socioeconómica próspera que conoce Venezuela gracias al petróleo permite el establecimiento de numerosas industrias en la localidad de Antímano. La población progresa rápidamente. Las familias cuyos ingresos se incrementan, acuden en mayor número a solicitar la inscripción de sus hijas en el Refugio, contribuyendo a su transformación y a su desarrollo.

El auge industrial ${ }^{25}$ de Antímano transparenta en el aumento de las matrículas de alumnas externas. La Madre Saint Jacques, Superiora Regional de las Hermanas de San José de Tarbes, autoriza la apertura de los seis grados de primaria, transformando, para la circunstancia, en aulas, las intalaciones de la lavandería. La ayuda financiera del Consejo Venezolano del Moño ${ }^{26}$ que concede veinte becas y la de la Asociación de Damas Bolivarianas que otorga diecisiete becas para el sostenimiento del internado, facilitan también la prosecución, construcción e instalación de cinco aulas amplias y confortables (Archivos de Antímano). 
Con una sola entrada por la calle Real, un pequeño jardín, el recibo y la portería, la casa-escuela se va modelando poco a poco, transformándose en un hogar acogedor y placentero para centenares de niñas. Frente al jardín

que da hacia la calle, un nicho con la imagen de San $\mathrm{José}^{27}$ : a la gente que pasaba por la calle le llamaba la atención, algunos le tenían mucha devoción, le rezaban y le ofrecían promesas, lo llamaban « San José de Antímano » (Archivos de Antímano).

El Refugio cuenta ya con varias habitaciones, una enfermería y una sala de Comunidad. Después de la capilla se encuentra un pasillo algo amplio que, al principio, sirve de salón de clase y donde, además, se coloca parte de las niñas internas, ya que la Capilla no es suficiente. Luego vienen el comedor y el estudio de las internas ${ }^{28}$.

Cuenta una ex alumna Haydée J. Carrillo A. :

(...) érase por allá el año de 1954, tenía para ese entonces cinco años en cuanto llegué a este colegio a iniciar mis estudios; me veo llegar a las $8: 00$ de la mañana de la mano de mi mamá ; recuerdo que la entrada era por donde hoy es la entrada del estacionamiento ; había una gran pared con rejas en su interior un jardín y, a mano derecha, una acera que conducía a la entrada principal ; por cierto que la puerta es la misma que está en la entrada principal ; al entrar al Colegio había una imagen de San José, de frente una puerta que conducía a la capilla, a mano izquierda un pasillo con sillas y, al final del mismo, estaba la Dirección, siguiendo a mano derecha, había un baño, luego seguía donde se encontraban unos bancos largos, donde una se sentaba a esperar que tocaran la campana para bajar a los salones ; donde está actualmente la biblioteca, eran los dormitorios de las internas ; a mano derecha había otro salón grande donde luego estaba la dirección ; existía allí mismo un cuarto de enfermería, lo recuerdo porque muchas veces me estuve allí con dolores de estómago.

Al bajar las primeras escaleras recuerdo que había una gruta grande hecha de piedras con muchas plantas, muchos maticos de helecho y malanga, piedras y agua (ahí se venera la imagen de la Virgen de Lourdes); en ese mismo patio existía unas duchas y especies de lavandero, todo esto donde actualmente está la gruta, para aquel entonces el patio inferior era de tierra con piedras y existía un parque (Archivos de Antímano).

La precisión de los recuerdos, la emoción que de ellos se desprende dice mucho sobre el clima de convivencia que las religiosas han logrado crear y la compenetración, patente, entre la escuela, nuevo hogar, y las alumnas.

\section{Con la democracia representativa..}

La renta petrolera en ascenso tranforma profundamente la economía nacional venezolana. Factor clave en la modernizacón impulsada por el capitalismo delEstado hacia la modernización favorece la creación de un mercado interno próspero y facilita el desarrollo de una nación antes condicionado por la agricultura y la tradicional exportación agropecuaria.

Asimismo, la caída de la dictadura del presidente Marcos Pérez Jiménez en 1958 marca el inicio de la democracia representativa en Venezuela. La firma, el 31 de octubre, del pacto de Punto Fijo en vísperas de las elecciones presidenciales de diciembre, por los tres grandes partidos nacionales (Acción Democrática, Social Cristiano COPEI y Unión Republicana Democrática), conforta los mecanismos democráticos. La política educacional se fundamenta como factor de desarrollo económico, legitimando el aumento del gasto público en beneficio del capital humano, agente esencial en la lucha contra las desigualdes.

La Constitución de 1961 que retoma la tesis del Estado Docente planteada en las proposiciones legislativas de 1947 y 1948, al señalar que la educación es obligatoria, una responsabilidad de los padres y representantes y un deber del estado (Art. 55) refuerza este concepto. Las Hermanas de San José de Tarbes convencidas, por su parte, de la necesidad de generar procesos que acompañen al alumno/a en su crecimiento humano-cristiano, brindan y valoran una educación que permita el desarrollo y el crecimiento de la persona. La coherencia de su formación, el rigor, la disiciplina y, sobre todo, una aptitud marcada hacia la orientación vocacional favorecen el incremento del número de matrículas entre los colegios de la congregación, el del Refugio, en particular.

La construcción de una serie de locales destinados a aulas para Preparatorio, ropería, baños, cocina para el internado ritma el indicio de satisfacción de la comunidad hacia las religiosas. En 1965, incluso, bajo la administración de la Hermana San Pablo, se edifica el primer departamento de las religiosas, dotado de habitaciones individuales muy sencillas y cómodas (Archivos de Antímano).

Desafortunadamente, a raíz del terremoto que asola Caracas, en 1967, la vieja casona del siglo pasado queda prácticamente destruida. Es necesario derribarla y, en su lugar, se acondiciona un patio de recreo que, luego, servirá de estacionamiento. En esa misma oportunidad, se abre una nueva entrada al Refugio por la parte del bulevar. La Iglesia y la Casa parroquial dañadas por el sismo, el Colegio cede parte de sus instalaciones (Archivos Casa Provincial) para las celebraciones litúrgicas y el funcionamiento del despacho parroquial, mientras se efectúan las reparaciones.

Ha cambiado la política del Estado hacia la educación privada. Más flexible y tolerante, sigue ejerciendo sobre los planteles privados (y públicos) el control necesario para garantizar la eficiencia educativa, la higiene, la moralidad y el orden público ; pero, al mismo tiempo, asegura a los docentes un régimen de trabajo y un nivel de vida acordes a su « elevada misión ». Es protegida la educación privada con tal de que imparta los principios contenidos en la 
Constitución.

El cambio constitucional en que es reconocida la familia como « célula fundamental de la sociedad» es esencial en una sociedad en que el matrimonio nunca ha sido una institución generalizada. En el Refugio donde se atiende a niñas procedentes en su gran mayoría de familias descompuestas o para quienes las circunstancias del nacimiento, natural o ilegítimo no quedan claramente definidas, no ha esperado este reparo para construir hábitos de vida en el seno de la escuela. Reina en ella un clima de libertad, de espontaneidad, de autonomía y de autoactividad propicias para que se conjuguen hábilmente democracia y educación.

\section{Nuevos tiempos}

Ahora bien, las décadas de los sesenta, setenta está marcada por un proceso de modernización general del sistema escolar venezolano. La Educación Básica se inicia ahora con la implementación del Ciclo Básico Común y el Ciclo Diversificado. La finalidad es claramente definida y orientada hacia el desarrollo del pensamiento reflexivo y crítico, " para actuar con eficacia en la vida ». Se trata de :

Motivar al alumno para el ejercicio de la responsabilidad : consigo mismo, los semejantes, la comunidad y la naturaleza (R. A. Uzcátegui, 1996, s.n.p.)

Para ello, se propone el Estado, mediante el IV plan de nación (1970-1974) de :

Alcanzar una sociedad democrática y participante donde cada persona encuentre las condiciones y oportunidades para su liberación y exige que la educación se ubique dentro del proceso histórico de las transformaciones sociales para acelerarlo. En este sentido, la educación, además de ofrecer sus cometidos transcendentales y universales, debe contribuir a la formación de una conciencia crítica para la creación y difusión de innovaciones, convirtiéndose en un medio de promoción social. Los conocimientos y valores transmitidos por el proceso educativo deben orientarse también hacia el logro del desarrollo socio-político y preparar a la población para el ejercicio de la libertad (R. A. Uzcátegui, 1996, s.n.p.).

Promoción social en perfecta adecuación con el proyecto educativo tarbesiano fundamentado en criterios de calidad y que quiere dar respuestas pragmáticas a los retos planteados por la educación en Venezuela.

La actitud de apertura manifestada por el Presidente de la República, Dr. Rafael Caldera ${ }^{29}$, hacia la Educación Privada Popular se concreta, en 1970, con la firma de un convenio con la A.V.E.C., mediante el cual el Ministerio de Educación le otorga un subsidio para equiparar los sueldos de los docentes del privado con los del sector oficial. El Refugio de la Infancia se beneficia con esta medida y puede así mantener sus pensiones al alcance de las clases populares.

Sin embargo, en 1974, la dirección del Refugio se ve obligada a cerrar definitivamente el internado. El alto costo de la vida, el retiro de las becas por parte de las instituciones otorgantes y un número reducido de religiosas para atender la escuela vencen las últimas resistencias. Ante la necesidad de duplicar las secciones de grado para responder a la demanda de cupos, las dependencias del internado son remodeladas para aulas, biblioteca, laboratorio y salón de reuniones.

Al mismo tiempo, se acentúa la pauperización de las capas más necesitadas. Un flujo enorme de población, campesina en su gran mayoría, procedente de los Andes, del Oriente y del centro del país, ilusionada por las posibilidades de acceso laboral en la ciudad capital, provoca una verdadera explosión demográfica en Caracas y en sus alrededores. Los barrios se multiplican de manera anárquica agudizando las condiciones de convivencia. Se fragiliza una población ya menesterosa y en los cerros cercanos al Refugio las condiciones de existencia se extreman.

Por si fuera poco, en 1978, la llegada de indocumentados procedentes de Colombia y la reubicación de damnificados por diversas calamidades públicas (inundaciones en particular) en los barrios de Mamera y de La Pedrera, en la parroquia de Antímano, aporta una nueva cuota de crecimiento poblacional y, con ella, las problemáticas derivadas de una mala $\mathrm{o}$ nebulosa gestión del proceso.

El Refugio, tradicionalmente, había privilegiado un alumnado femenino. A pesar de las recomendaciones del Ministro de Educación Samuel Darío Maldonado, en su tiempo, siempre se había resistido a establecer la escuela mixta en el plantel - también porque no disponía de las estructuras necesarias. La ampliación del colegio y las necesidades apremiantes de los habitantes de Antímano van a favorecer una toma de decisión que, además, cumple con los requisitos estatales ; sin embargo es muy tímido el primer ensayo :

Los alumnos, éramos solamente niñas, hasta que cursé el $6^{\circ}$ grado, cuando ingresaron dos varones ${ }^{30}$, recuerdo que al $5^{\circ}$ grado, creo que los admitieron para ensayar el sistema mixto, lo que sí estoy segura es que causaron un revuelo total entre las niñas (Archivos de Antímano).

En 1980, el sistema educativo venezolano sufre una transformación destinada a proyectarlo hacia un futuro más ambicioso y más conforme a las exigencias mundiales. El Decreto $n^{\circ} 646$ promulgado en junio, seguido, un mes después, por la de la Ley Orgánica de Educación, institucionaliza la educación básica en Venezuela. Su duración es comprendida en un período de 8 a 10 años y va acompañada de una obligación, antes de 1999, de la incorporación al sistema de todos los niños en edad escolar.

A este efecto, el Ministro de Educación, el Dr. Rafael Fernández Heres, inicia un proceso orientado a que funcione mejor la Educación Básica seleccionando 1312 planteles $^{31}$ para un primer ensayo. 


\section{Retos educativos}

Comprometido con la comunidad en proporcionar una educación dinámica, creadora, abierta al diálogo, que responda a las exigencias del país, permita la integración de los ciudadanos al proceso sociocultural y favorezca su autodeterminación, el Refugio, siguiendo el modelo público, se incorpora en la modalidad de Escuela Básica de $1^{\circ}$ a $6^{\circ} \operatorname{Grados}^{32}$.

La evaluación del proceso, en 1984, por la profesora Ruth Lerner de Almea, entonces Ministra de Educación pone de realce la necesidad de una formación docente acorde con las exigencias educativas :

Para la Educación Básica se corregirá la improvisación de ese nivel para lograr una integración de las acciones educativas, desde el primero al noveno grado. Se programará el desarrollo progresivo de ese nivel y se cumplirá con un sistemático programa de capacitación docente y de reformas organizativas de mejoramiento de las instalaciones y equipamiento de las escuelas básicas para lograr una acción educativa de alto rendimiento (J.L. Bastardo Salcedo, 1996, p. 142).

La comunidad del Refugio, por su parte, continúa acogida al régimen de subvención del Ministerio de Educación. Está formada por cinco Hermanas. Tres de ellas atienden, desde 1981, conjuntamente con la Parroquia, actividades anexas a su labor educativa, en el Centro de Promoción Social « Vuelta del Fraile ». Su objetivo es « caminar con la gente en el desarrollo de la organización comunitaria a través de la evangelización, la educación y la promoción » (Archivos de Antímano) mediante la misa dominical y las celebraciones litúrgicas, la catequesis dominical, los cursos de promoción Ince-Iglesia ${ }^{33}$, la educación de niños sin escuela, la alfabetización de Adultos y los grupos de mujeres animadoras de la comunidad.

El Plantel cuenta ya con 530 alumnos distribuidos en los niveles de Pre-Escolar y Básica $\left(1^{\circ}\right.$ a $6^{\circ}$ grados $)$ repartidos en trece secciones atendidas por catorce docentes $^{34}$. Su formación en la Universidad Católica Andrés Bello sigue los requisitos estatales en cuanto al rol de promotor, investigador y agente de cambio que han de desempeñar.

La organización del Refugio, su implicación constante en el quehacer cotidiano de la población desfavorecida, su eficiente administración de los recursos humanos, materiales y financieros, la formación y el acompañamiento de los padres y representantes en las relaciones del núcleo familiar concuerdan con lo expresado por el coodinador de la Comisión Presidencial para el Estudio del Proyecto Educativo Nacional (COPEN), Arturo Uslar Pietri :

(...) Ha de prestarse particular atención al aprendizaje del lenguaje y la matemática... La geografía y la historia han de ser el instrumento para el conocimiento de la tierra y la gente a la que pertenece el educando. Debe incluirse información más práctica que teórica sobre la evolución de las instituciones políticas, del funcionamiento del régimen republicano y de los derechos esenciales... Es conveniente destacar que la universalización de la educación preescolar y básica tiene que ser la primera prioridad educativa del Estado. Se deben garantizar los recursos financieros que exigen esos niveles (G. Luque, 1999, p. 281).

Cuidadoso de la excelencia académica, el Refugio sigue la vía que siempre se ha fijado de capacitar al educando como sujeto, no sólo de su propio desarrollo, sino también del desarrollo de la comunidad, fomentando una actitud de apertura que le permita comprometerse con sus hermanos en la construcción de un mundo más justo y humano (Hermanas de San José de Tarbes, 1996).

En efecto, el trato que las autoridades del Refugio han logrado construir con la población de la parroquia de Antímano facilita un intercambio responsable ; asimismo permite un compromiso susceptible no sólo de generar el fortalecimiento de la relación con el núcleo familiar sino también fortalecer la formación y acompañamiento en su misión de los padres y representantes.

La capacidad de apertura y de diálogo que manifiesta el centro educativo tarbesiano hace del Refugio un lugar privilegiado de vivencias. De ahí que, con motivo de la celebración del centenario de la Casa, aparezcan con frecuencia los términos de « hogar », de « familia » en los numerosos testimonios de ex alumnas del colegio.

(... ) Esto fue la etapa más feliz y triste porque yo sabía que me tenía que ir y dejar mi segundo hogar (los subrayados son nuestros) en donde jugaba, reía, aprendía y soñaba en ser parte de esta pequeña ciudad. [...] pertenecí a la Patrulla de Tránsito, nombraba a los alumnos por el micrófono a la hora de la salida, bailé y canté en todos mis grados, pertenecí a un Rosario humano que se realizó en las Naciones Unidas,... siempre desde que entré a este hogar (el subrayado es nuestro) siempre tenía algo que hacer y me gustaba porque me sentía útil y a la vez parte de esta gran familia...

(...) en mis tiempos de estudio aquí éramos solamente niñas y formábamos una gran familia en la que siempre existía un gran afecto.

(...) para mí es un gran orgullo pertenecer a esta gran familia, porque aun me siento parte de ella, los días más felices de mi infancia transcurrieron aquí, ya que para aquel entonces estudiaba hasta las cuatro de la tarde ; también recuerdo el rosario de todas las tardes a las $3: 00$, luego bajaba a hacer la limpieza del salón y al finalizar nos obsequiaban pan dulce con cambur... (Archivos de Antímano).

La educación proporcionada por las tarbesianas va más allá de la mera instrucción. Los valores fundamentales de familia, solidaridad, ayuda mutua son esenciales en la elaboración de la identidad del ser humano y de su pertenencia a un cuerpo bien definido.

Con este fin, adhiere al Plan Lector, promovido por la Resolución del 18 de septiembre de 1992, a partir 
del cual, se pretende fortalecer, por etapas, al nivel nacional, la lectura como medio más importante para la formación de hombres conocedores, participativos, críticos y creadores.

Pero, al mismo tiempo, el doble turno ${ }^{35}$ escolar adoptado en Venezuela como medida de urgencia para atender a una mayor población escolar y optimizar su rendimiento se revela una disposición infructuosa y nociva. El informe de Arturo Uslar Pietri, al respecto, es inapelable :

Las escuelas ubicadas en los sectores más desfavorecidos deben ofrecer los medios para que los alumnos reciban a través del plantel atención médico-asistencial y alimentación. El niño debe realizar en la escuela las tareas escolares y diversas actividades complementarias que contribuyan a su desarrollo físico, intelectual, social y cultural, con el manejo de sus manos en un quehacer provechoso. Para ello es necesaria una mayor permanencia del alumno en la escuela, mediante la ampliación del horario escolar que comprenda las horas hábiles de la mañana y de la tarde. Una escuela efectivamente vinculada a su comunidad debe permanecer abierta durante todo el año (R.A. Uzcátegui, 2006, s.n.p.).

Consciente de esta falla en el sistema educativo, el Refugio no espera esas conclusiones para valerse de un régimen en que el estudio se fundamenta en el uso de los dos turnos, como medida indispensable para una igualdad de acceso a la educación y al desarrollo ciudadano para los hogares de bajo ingreso.

Decisión que se apoya en parte en la imposibilidad material y estructural del Refugio para satisfacer las exigencias ministeriales, formuladas en 1987, de una Escuela Básica implementada hasta el $9^{\circ}$ grado. También se explica por la cesión de una parte de su planta física al « Instituto Radiofónico » Fe y Alegría ${ }^{36}$, para un Centro de Alfabetización de Adultos.

Sin embargo, no pierde de vista sus objetivos de calidad. Finalidad concretada en otro ámbito a través de la organización de un servicio de Orientación a los padres, para, con él, formar la Escuela de Padres, el Voluntariado de Padres y los Animadores de los movimientos eclesiales y vecinales de la Parroquia de Antímano.

Paralelamente, amplía y profundiza la formación docente merced a la instauración, en el mismo Refugio, de un Centro de Pasantes para estudiantes de $4^{\circ}$ año de Psicología de la Universidad Católica Andrés Bello (U.C.A.B.).

Esto evita situaciones poco habituales en que el Refugio corre el riesgo de perder el prestigio tan celosamente ganado entre la población pobre de la comunidad :

En tercero pasó como una cosa muy bonita, mi mamá y las mamás de otros compañeros fueron a darnos clases porque la maestra tenía un problema y no había suplentes en ese momento. Esos momentos fueron de mucha alegría y diversión... (Archivos de Antímano)

Los proyectos pedagógicos de Plantel (PPP) esbozados por la Reforma Educativa de 1997 aparecen como un intento por « adecuar los procesos de enseñanza y aprendizaje a la auténtica realidad social y personal que viven los alumnos y las alumnas » (R.A. Uzcategui, 2006). Sustentada en los principios de libertad, descentralización, autonomía, reflexión e innovación, dicha reforma cumple con el espitu tarbesiano en que ha de prevalecer la formar de la conciencia y del corazón en todas las circunstancias en que « la obra educadora lo permite » (Archivos del Refugio).

Seguirá luego un año de transición política entre 1998-1999. Desembocará en la elección del Presidente Hugo Chávez y con él nuevas perspectivas educativas. ¿Se mantendrá el Refugio ? ¿Tendrá que adoptar otra vía ? Ilusiones o desilusiones... ¿ Cuál será su destino?...

Empieza una nueva etapa, otra historia.

\section{Referencias}

“A.V.E.C. en Asamblea Anual Aprueba Proyecto Educativo Católico", Caracas, Revista 32-33, diciembre de 1986, 86 p.

"A.V.E.C. Observaciones al articulado sobre educación de la Nueva Constitución", Caracas, 23 de noviembre de 1996.

Bernoville, Gaétan, Terre de Bigorre. Les Sœurs de SaintJoseph de Tarbes, Paris, Bernard Grasset Éditeur, 1961, 334 p.

Bravo Jaúregui, Luis, La escuela venezolana. Educación de masas.Políticas y resultados a partir de 1958, Caracas, Editorial Episteme, 1999, 95 p.

Fernandez Heres, Rafael, La educación bajo el signo de la Ecuela Nueva (1936-1948), Caracas, Fuentes para la Historia Republicana de Venezuela, 1997, 272 p.

Gay-Sylvestre, Dominique, Unuma Tejemonae. De Cantaous à Coromoto : l'œuvre des religieuses de Saint-Joseph de Tarbes (1843-2000), Limoges, Pulim, 2004, 334 p .

Hermanas de San José de Tarbes, Provincia de Venezuela, Centros educativos Tarbesianos. Proyecto Educativo, Caracas, Casa Provincial, 1996, 35 p.

Luque, Guillermo, "Público y privado en educación: vigencia del Estado Docente en la reconstrucción de una nación democrática", in Revista de Pedagogía, Caracas, volumen XX, n59, septiembrediciembre de 1999, pp.263-289.

Salcedo-Bastardo, José Luis, Historia fundamental de Venzuela, Caracas, Universidad Central de Venezuela, Ediciones de la Biblioteca, Undécima Edición, 1996, 649 p.

Uzcátegui, Ramón Alexander, "La Educación básica en Venezuela. Reforma, proceso e innovación a partir de 1986", Caracas, Escuela de Educación, Universidad Central de Venezuela, marzo de 2006, s.n.p.

Uzcátegui, Ramón Alexander (A), “Algunos rasgos conceptuales e históricos para caracterizar Estado Docente en Venezeuela", Escuela de Educación -UNIMET, Escuela de Educación Universidad Central de Venezuela, sin fecha, s.n.p.

Uzcátegui, Ramón Alexander (B), "Algunos rasgos conceptuales e históricos para Caracterizar el Estado docente en Venzuela", Caracas, Escuela de Educación-UNIMET, Escuela de Educación Universidad Central de Venezuela, sin fecha, s.n.p.

Viso, Carlos R., Educación y salud en la modernización capitalista de Venezuela (1936-1945), Caracas, Secretaría, Universidad Central de Venezuela, Fondo Editorial Tropykos, 1999, 167 p.

Archivos (Caracas, Venezuela)

Casa Provincial

Relato de la Hermana Celina, quien recibió la Obra de manos de la señorita Duplat, la fundadora, Archivos de las Hermanas de 
San José de Tarbes, Antímano, sin fecha, sin número de páginas.

\section{Notas}

1 Ver al respecto mi artículo « Las Hijas de la Caridad del 'Buen Pastor' de Angers : una obra misionera en La Habana (18791961) », rencontre internationale sur Europe-Amérique Latine à l'aube du troisième millénaire. Regards croisés. Ouvrage collectif édité par la Red Túpac Amaru - Micaela Bastidas -, Programa ALFA de la Comunidad Europea de Cooperación entre Universidades Europeas y Latinoamericanas, Lima, Universidad de San Marcos, 2001, pp. 47-57, 533 p.

2 Creada en 1843 en la pequeña aldea francesa de Cantaous en el sur de Francia.

3 Juan Pablo Rojas Paúl, Presidente de Venezuela desde el 5 de julio de 1888 hasta el 18 de marzo de 1890.

4 El hospital Vargas, acabado de construir en 1891, concebido en grande, debía contar con mil camas. Estaba destinado desde un principio a la enseñanza. En realidad, fue un gran centro para cirurgía y maternidad. La labor humanitaria que en él se desempeñó fue de gran alcance.

51890 : huerfanato Padre Febres-Cordero en Valencia ; 1891 : hospital José María Vargas en Caracas y colegio Nuestra señora de Lourdes en Valencia ; 1892 : internado en la casa San Juan en Caracas, colegio Sagrado Corazón de Jesús en Puerto Cabello, administración del manicomio de Catia en Caracas; 1893 : hospital civil en Valencia ; 1897 : hospital La Caridad en Barquisimeto ; 1898 : el Externado de San José de Tarbes en Caracas ;

1902 : Internado de San José de Tarbes (futuro Paraíso) en Caracas ; 1903 : hospital San Juan de Dios en La Guaira ; 1907 : leprosería de Cabo Blanco ; 1909 : colegio en La Guaira; 1918 : fundación del Patronato de San José de Tarbes en Caracas ; 1949 : fundación del colegio de La Florida en Caracas...

Ver al respecto D. Gay-Sylvestre, Unuma Tejemonae. De Cantaous à Coromoto : l'œuvre des religieuses de Saint-Joseph de Tarbes (1843-2000), Limoges, Pulim, 2004, 334 p.

6 La palabra Antímano es un acrónimo derivado de los términos Atamanona y Amatima, que eran los nombres de los dos grupos indígenas que habitaban la localidad en la época precolombina. La denominación de Antímano se establece en 1621. La Parroquia del mismo nombre es una de las 32 parroquias que forman parte de Caracas y una de las 22 que se encuentran dentro del Municipio Libertador. Limita al norte con las parroquias El Junquito y Sucre; al sur con las parroquias Macarao y Caricuao; al este limíta con las parroquias El Paraíso y La Vega; al oeste limita con el Estado Vargas. Está integrada por los sectores: Antímano, Carapita, La Yaguara y Juan Pablo II, el primero está conformado por los barrios Las Delicias, Vidal López, Santa Ana, Las Clavellinas, Germán Rodríguez, El Refugio, La Redoma, La Acequia, El Carmen, Vuelta del Fraile, Germán González, La Gruta, La Grama, La Colmena, La Quebrada, Matapalo, Subida de la Pedrera, El Rosario y Buena Vista, además del casco histórico de Antímano.

7 Cada municipio se divide en parroquias, el menor rango político-territorial asignado, creadas con el objeto de descentralizar la administración municipal. Las parroquias son consideradas demarcaciones de carácter local creadas con el objeto de descentralizar la administración municipal y para la división de Jefaturas Civiles, que equivalen a tribunales locales encargados del ámbito jurídico. Estas localidades no tienen ámbito administrativo, y a su vez se dividen en barrios y urbanizaciones. En Caracas existen 32 parroquias.

8 La Parroquia Santa Rosalía es una de las 32 parroquias que forman parte de Caracas y una de las 22 que se encuentran dentro del Municipio Libertador. Está ubicada al centro-sur del Municipio Libertador. Limíta al norte con las parroquias Catedral y Candelaria; al sur con la Parroquia El Valle; al este limita con las parroquias San Agustin y San Pedro y al oeste con las parroquias Santa Teresa, El Paraíso y La Vega.

9 Presidente del 20 de febrero de 1898 al 23 de octubre de 1899.

10 En particular en el hospital Vargas.
11 Anteriormente llamada Ocumare del Tuy, la ciudad de los Teques, ubicada cerca de la capital, Caracas, es, desde el año de 1927, la capital del estado Miranda y a su vez, capital del municipio Guaicaipuro.

12 Se desata en el puerto de La Guaira a fines de 1908, probablemente procedente de unas ratas, encontradas en un barco, portadoras de la infección.

13 La madre Saint-Simon sale de Francia, el 24 de mayo de 1889, para instalar en Caracas la primera misión de las Hermanas de San José de Tarbes. Ver al respecto D. Gay-Sylvestre, Unuma Tejemonae. De Cantaous à Coromoto : l'œuvre des religieuses de Saint-Joseph de Tarbes (1843-2000), Limoges, Pulim, 2004, 334 p.

14 Ocupará el cargo de Presidente de la República de 19 de diciembre de 1908 al 17 de diciembre de 1935.

15 Para 1910 el Gobierno de Venezuela mantiene tres hospitales para leprosos en su territorio : dos en el estado Zulia (Lazareto Nacional «Maracaibo» y Leprosería Nacional «Isla de Providencia») y uno en el Distrito Federal (Leprosería Nacional «Cabo Blanco»). Esta leprosería, cercana a la capital es cerrada y transferida cerca de Maracaibo.

16 Ver al respecto D. Gay-Sylvestre, Unuma Tejemonae. De Cantaous à Coromoto : l'cuvre des religieuses de Saint-Joseph de Tarbes (1843-2000), Limoges, Pulim, 2004, 334 p.

17 Al igual que los agentes de la instrución pública.

18 El Código de 1912 contiene precisas disposiciones sobre el control y la vigilancia del Ministerio de Instrucción pública sobre el funcionamiento de las escuelas privadas, en particular las atendidas por religiosos (as) católicos (as).

19 Este decreto establece el funcionamiento de la instrucción pública « siempre y cuando no atente la moral y el orden público ».

20 La libertad de enseñanza establecida en el Decreto de 1914 servirá de apoyo en el intenso desarrollo de la iniciativa religiosa en la fundación de colegios católicos.

21 Ver al respecto D. Gay-Sylvestre, Unuma Tejemonae. De Cantaous à Coromoto : l'œuvre des religieuses de Saint-Joseph de Tarbes (1843-2000), Limoges, Pulim, 2004, 334 p.

22 La madre Marie-Germaine sustituye a la madre SaintSimon. Ésta vuelve a Cantaous (casa madre en Francia) para la elección de la Superiora general de la congregación. Enferma, no podrá regresar a Venezuela y fallecerá en 1919 en el mismo pueblito desde donde había salido para el nuevo mundo 30 años antes.

23 Ex Presidente de Venezuela del 19 de marzo de 1890 al 17 de junion de 1892 .

2430 de diciembre de 1943

25 En los años 40 se establece en Antímano la primera planta de cervecería Polar. Luego se instala la fábrica de Pepsi-Cola Venezuela que después será adquirida por Coca-cola y en 1948 se funda la empresa Siderúrgica Venezolana (Sivensa, hoy Sidetur).

26 Asociación privada caritativa.

27 Actualmente está al lado de la Capilla.

28 Donde están actualmente el recibo y la adminitración.

29 Rafael Caldera (2 de marzode 1969 a 12 de marzo de 1974).

30 Con la idea de fortalecer institucionalmente el sistema educativo, el Ministro establece las líneas maestras que orientarán las políticas educativas del Gobierno, entre otras la de planteles mixtos.

31 Los otros planteles (11.831 en total), siguen rigiéndose por la Ley Derogada in R. Uzcátegui, La educación Básica...

32 De la evaluación llevada a cabo por el Ministerio de Educación, en 1984, respecto al hecho de expandir o no el ensayo de la Educación Básica a nuevos planteles, se implementan en todo el país los tres primeros grados de la Educación Básica y se establece la división en tres etapas de tres años cada una. Para el año escolar 1986-87 se implantan los $4^{\circ}, 5^{\circ}$ y $6^{\circ}$ grados luego en el año $1987-88, \operatorname{los} 7^{\circ}, 8^{\circ}, 9^{\circ}$ grados. También se dan cambios en las finalidades y contenidos de cada una de las etapas.

33 Instituto Nacional de Capacitación Educativa (INCE) Iglesia.

34 Hay, además, tres empleados administrativos y cuatro 
obreros.

35 Sistema destinado a permitir una masificación de la asistencia escolar en que unos niños van a la escuela por la mañana y otros por la tarde.

36 Instituto dedicado a la educación popular.

Recebido: 05/05/2010

Última Revisão: 16/06/2010

Aceite Final: 21/06/2010

Sobre o autor

Profesora Dominique Gay-Sylvestre - Catedrática de civilización latinoamericana Directora del equipo de investigadores Dinámica y Retos de la Diversidad (DYNADIV) Facultad de Letras y de Ciencias Humanas 